International Journal for Educational Integrity

\title{
A survey of Samford University students regarding plagiarism and academic misconduct
}

\author{
Professor Robert H. Schrimsher \\ McWhorter School of Pharmacy, Samford University \\ rhschrim@samford.edu
}

Lori A. Northrup

University Library, Samford University

lanorthr@samford.edu

\author{
Susan P. Alverson \\ McWhorter School of Pharmacy, Samford University \\ spalvers@samford.edu
}

Keywords: plagiarism, academic misconduct/integrity, cheating, survey

\begin{abstract}
The purpose of this study was to obtain students' attitudes and opinions at Samford University regarding plagiarism and academic misconduct by means of an internetbased survey system composed of yes/no questions and Likert-type rating scales. Data from 681 of approximately 4,500 Samford University students (15\% return rate) were analysed. Research indicates that plagiarism and other incidents of academic misconduct are on the rise for a variety of reasons. Students seemingly have the notion that internet information is public knowledge and is thus free from intellectual property rights; therefore, they do not seem to think internet information needs to be cited for academic purposes. The vast majority of Samford students agreed that if one submits a paper written by someone else, this would constitute plagiarism; and that it was unacceptable to copy/paste information from the internet without proper citations. Slightly less than a majority of students disagreed that cheating was widespread at Samford; and a majority indicated that faculty should clarify their expectations regarding academic integrity. The results are somewhat similar to other plagiarism and academic misconduct studies.
\end{abstract}

\section{Introduction}

Plagiarism and academic misconduct appears to be steadily increasing across college and university campuses not only in American higher education settings, (Graham, Monday, O'Brien, \& Steffen, 1994; Genereux \& McLeod, 1995) but also within other groups such as scholarly and scientific communities, political offices and journalistic groups (Ercegovac \& Richardson, 2004).

The popularity, usage, and primarily the accessibility of the internet have likely catapulted plagiarism to a new height. With the advent of the internet, plagiarising someone else's work now requires just a few strokes of the keyboard (Dye, 2007; Kraus, 2002). Unfortunately, even when this apparent student 'cut-and-paste' mindset is acknowledged, the extent of plagiarism and academic misconduct is likely much worse than it appears. Recent studies have indicated that students plagiarise

The International Journal for Educational Integrity is available online at:

http://www.ojs.unisa.edu.au/journals/index.php/IJEI/

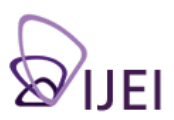


from both conventional and internet sources; however, McCabe posits, based on students' self-reported attitudes, that high school students may not consider cuttingand-pasting from the internet to be cheating (McCabe, 2001). The significance of this student view combined with the increase in plagiarism among university and college students is enormous. Kraus expands this notion by being "convinced that a rapidly growing number [of students] simply do not see plagiarism as wrong. ... They recognize that they should not do it, but they understand our concern over it as an almost quaint prohibition. It has become a misdemeanor in the eyes of a new generation, something on the order of jaywalking or sneaking a grape while shopping for produce" (Kraus, 2002, p. 84). There is no way to ascertain with certainty how students have arrived at this conclusion; however, further scrutiny of students' attitudes toward plagiarism may provide additional insight.

\section{Why do students cheat?}

Many factors have been proposed for why students cheat or plagiarise. In referring to high school students, McCabe states that increasing pressure from parents and increasing difficulty of the material being taught are leading factors in students' decisions to cheat, and that the declining influence of parents and teachers is even more important. He notes, however, that teachers and parents are doing little to combat the problem. Students, according to McCabe's (2001) research, felt that teachers do not really care about cheating, probably due to the bureaucratic procedures involved in pursuing such allegations. While the focus of this particular research was on high school students, many high school students eventually attend college. If their mindset is not altered, then their attitudes will transfer into their college environment. McCabe adds an interesting comment regarding the internet: younger students, for whom the internet is such a common form of communication, seem to have difficulty understanding its proper use as an academic tool. The "Internet is believed to be public knowledge and does not need to be footnoted-even if it is quoted verbatim" (McCabe, 2001, p. 41).

Probably a more revealing study by McCabe in the mid-nineties of almost 1,800 students at nine medium to large universities examined the relative contextual and individual factors influencing cheating behavior. The results indicated that "contextual factors (peer cheating behavior, peer disapproval of cheating behavior, and perceived severity of penalties for cheating) were significantly more influential than the individual factors (age, gender, GPA, and participation in extracurricular activities). Peer-related factors once again emerged as the most significant correlate of cheating behavior" (McCabe, Trevino \& Butterfield, 2004, p. 222). Obviously, these types of factors are very difficult to analyse and predict because of their very nature.

A discussion regarding academic misconduct, which includes plagiarism, would not be complete without some discourse on situational ethics as it pertains to students. Essentially, under the precise circumstances, such as not being prepared for an assignment or exam, a student could be stressed to the limit and succumb to either 'cutting and pasting' from the internet without proper citation for the assignment or cheating on an exam due to not being prepared. The reasons for this very risky behaviour could be numerous. Anyone who has been a student has been in these situations to some degree, but it does not necessarily mean that academic misconduct was the result. McCabe categorically states that "The ethics of cheating is very situational for many students" (McCabe, 2005, p. 28). Some students are simply willing to take the risk, especially if they feel that they may fail anyway or do poorly in class (Kraus, 2002). Graham et al. (1994) found that of the three top reasons students reported as reasons to cheat, number two was that they did not have sufficient time to study.

Finally, although the Samford plagiarism survey did not address the question/issue of unintentional plagiarism, this issue is also worthy of some discussion. Unintentional 
plagiarism generally occurs when one plagiarises in some manner, without intending to plagiarise, and while not recognising that the manner of information use was wrong. This is a difficult issue to address. If a student plagiarised and there was no intent to do so, did plagiarism really occur? Faculty have strong emotional responses to plagiarism (Wood, 2004), probably whether unintentional or not. Even if the student did not intend to plagiarise, the faculty member may charge the student with some type of ethics violation. This is very much a crime and punishment model. Isserman questions whether or not plagiarism is truly a black-and-white issue and analyses the implications of such a clear-cut style of judgment. "Where do we draw the line between fair and fraudulent uses of others' words and ideas? Isn't there a big grey area? And if we are all guilty of straying into that grey area of unintentional plagiarism, haven't we forfeited the right to judge others, including those whose plagiarism may have been more purposeful" (Isserman, 2003, p. 12)? Another complication of unintentional plagiarism is that students likely desire simply to complete their research assignments. The complexity of performing research assignments, particularly in early college years, can be overwhelming; thus, inadvertent plagiarism is very likely to occur. Madray's conclusion is very similar from surveying 326 freshmen students from a possible pool of approximately 900 . "Most students want to complete their research assignments honestly but find it difficult, simply because they are clueless on how to accomplish it. Doing research is an involved and detailed process that requires the ability to find, analyze, and synthesize information while applying the appropriate rules of grammar and citation. The concept of interpreting and implementing the rules of plagiarism - to take information from varied sources and knead it into one's own research writing - proves to be challenging and confusing for students" (Madray, 2007, Conclusion section, para. 2).

Academic dishonesty, plagiarism, cheating, etc., are all related terms which overlap each other with similar meaning. For an excellent bibliography, Rebecca Moore Howard (2008) has compiled an extensive internet bibliography in this area that is quite useful. Ercegovac and Richardson (2004) have also compiled an excellent bibliography on plagiarism.

\section{Samford University}

Samford University, located in Birmingham, Alabama, is a Christian, private, four-year university established in 1841, with approximately 4,500 students enrolled, including about 2,800 undergraduate and 1,600 graduate students. Samford's major Schools are Arts and Sciences, Business, Divinity, Education, Nursing, Performing Arts, Law, and Pharmacy. The Schools of Law and Pharmacy offer the juris doctor (JD) and doctor of pharmacy (PharmD) degrees, respectively. The Schools of Education and Divinity likewise offer a doctor of education and a doctor of ministry degree, respectively. A master's degree is offered in various disciplines within the Arts and Sciences, as well as in Nursing, Business, Divinity, Education, Music, and Law.

The Samford University Student Handbook specifically delineates what constitutes academic integrity. Students' '[a]ctivities and attitudes should be consistent with high academic standards and Christian commitment, and should be in keeping with the philosophy and mission of the university ... They must be willing to observe high standards of intellectual integrity; they must respect knowledge and practice academic honesty" (Samford University, 2007). Students who do not practice academic integrity have violated the University's values system. Values violations are subdivided into five major areas: taking information, tendering information, plagiarism, conspiracy, and misrepresentation. The plagiarism section explicitly cautions against: "copying homework answers from your text and handing them in for a grade; quoting text or other works on an exam, term paper or homework without citing the source; submitting a paper purchased from a term paper service or acquired from any internet source; submitting another's paper/project as your own; taking a paper from an organization's files and handing it in as your own" (Samford, 2007, p. 119). 


\section{Purpose}

The purpose of this study was to obtain attitudes and opinions of students at Samford University regarding plagiarism and academic misconduct. A second rationale for this study was to compare these findings with similar research.

\section{Methodology}

The plagiarism and academic misconduct survey was intended only for Samford students, and all students, including undergraduate, graduate and part-time students, were afforded the opportunity to participate in the plagiarism survey. Any student in a valid degree-granting program at Samford University was eligible to participate in the survey. Encouragement to participate in the plagiarism survey was achieved via news bulletins, listserv messages to students, and faculty advocacy. Participation in the study was further enhanced by affording students an opportunity to participate in a drawing for a $\$ 100$ Samford University Bookstore gift certificate. No authentication or log-in procedure was required in order for students to complete the survey.

A pre-survey webpage was created depicting information prior to respondents taking the survey, which thanked the respondents for participating and emphasised the anonymity of the respondents and the opportunity for participating for a gift certificate drawing. The survey instrument (see Appendix A) consisted of the authors' definitions of plagiarism and academic misconduct, a few demographic questions, and both yes/ no and Likert-type questions.

Demographic data included information about classification and majors. Students were requested to select their academic classification (freshman, sophomore, junior, senior, graduate student, or other) from a drop-down menu at the beginning of the survey. The respondents were also requested to select their academic major by School, i.e., School of Arts and Sciences, Business, Divinity, Education and Professional Studies, Law, Nursing, Performing Arts, or Pharmacy. The Schools of Law, Divinity, and Pharmacy are strictly graduate programs. Other Schools have both undergraduate and graduate students. Respondents that selected their School as Arts and Sciences were further requested to select their major area of study, e.g., history, English, biology, geography, psychology, etc.

The Likert-type questions used a 5-point scale ranging from strongly agree, agree, undecided, disagree, to strongly disagree. All questions pertained to the Samford University environment. After the respondent submitted the survey, they were directed to a post-survey webpage, which again thanked the respondent for participating and afforded them the opportunity to submit their name for the gift certificate drawing and again emphasised the anonymity of their participation.

The survey was accomplished online (internet) via PHPESP (commonly referred to as PHP), which is a web-based survey tool. PHP scripts allow non-technical users to create and administer surveys, gather results, download data and view statistics (PHPESP, 2008). The survey was released on October 21, 2007, and closed on December 10, 2007 (end of semester). The survey was completely anonymous and there was absolutely no way a respondent could be identified. The survey instrument was approved by the Samford University Institutional Review Board (IRB).

Returned survey data were exported from PHP and entered into an SPSS $₫$ for Windows (version 15) data file for analysis. All analyses and tables were generated from the SPSS functions. Furthermore, all analyses were accomplished by descriptive statistics, one-way analysis of variance (ANOVA), or chi-square. 
The authors sought to answer six research questions with this survey. All questions pertained to the Samford University environment.

1. Had the student cheated on tests or exams?

2. Does it constitute academic misconduct if one submits a paper written by someone else, either in part or whole?

3. What were students' opinions regarding the acceptability of copying/pasting passages from the internet without citing the original source?

4. What is the estimate of the degree of cheating at Samford University?

5. Does it constitute plagiarism if one changes words from a source and then uses the rewrite without documentation?

6. Do students desire that faculty clarify very specifically their expectations for academic integrity for any course taken?

\section{Results}

There were 681 responses to the plagiarism and academic misconduct survey. The 681 student responses represent approximately $15 \%$ of the total student body. A sample of this size ensures accurate results to within $\pm 3.5 \%$ with $95 \%$ confidence.

Table 1 depicts the respondents' distribution by academic classification. Several of the analyses will be grouped by academic classification.

Table 1:

Academic classification of student respondents

\begin{tabular}{|l|c|c|c|}
\hline $\begin{array}{l}\text { Academic } \\
\text { Classification }\end{array}$ & Frequency & $\begin{array}{l}\text { Percent } \\
\text { of Respondents }\end{array}$ & $\begin{array}{l}\text { Percent of } \\
\text { Classification Group, } \\
\text { Fall 2007 }^{2}\end{array}$ \\
\hline Freshman & 187 & 27.5 & 20.0 \\
\hline Sophomore & 140 & 20.6 & 21.6 \\
\hline Junior & 100 & 14.7 & 18.1 \\
\hline Senior & 130 & 19.1 & 17.9 \\
\hline Graduate student & 124 & 18.2 & 7.63 \\
\hline Total & 681 & 100.0 & 15.2 \\
\hline
\end{tabular}

a'Source: http://ops.samford.edu/oie/factbook2007_2008/enrollment.aspx

A review of Table 1 shows that there is a relatively even distribution among academic classifications of respondents, except for the freshman and junior groups.

Table 2 represents the respondents' distribution by School. Noticeably, School representation is unequal, with the School of Arts and Sciences having by far the most respondents. On the survey, respondents were also requested to indicate their major of study within the School of Arts and Sciences; however, a breakout of academic majors within arts/sciences is not depicted, since several academic departments within arts and sciences are exceptionally underrepresented. 
Table 2:

Student respondents by schools

\begin{tabular}{lcc}
\hline School & Frequency & Percent \\
Arts and Sciences & 274 & 40.2 \\
Business & 55 & 8.1 \\
Divinity & 27 & 4.0 \\
Education and Professional Studies & 104 & 15.3 \\
Law & 25 & 3.7 \\
Nursing & 95 & 14.0 \\
Performing Arts & 45 & 6.6 \\
Pharmacy & 56 & 8.2 \\
\hline
\end{tabular}

\section{Results of research questions}

The first research question pertained to whether or not students had previously cheated on tests or exams. This was a yes/no question (see Appendix A, question 10). Table 3 , which is a cross-tabulation of academic classifications and question 10 , clearly illustrates that the majority (students) of all academic classifications indicated that they have not previously cheated on a test/exam. A chi-square contingency table was calculated and the likelihood ratio chi-square was not significant at the 0.05 alpha level $\left(x^{2}=2.721, d f=4, p=0.61\right)$.

Table 3

Cross-tabulation of academic classification by previously cheated on test/exam

\begin{tabular}{|l|l|l|l|l|l|l|}
\hline & \multicolumn{1}{|c|}{$\begin{array}{c}\text { Freshman } \\
(\%)\end{array}$} & Sophomore & \multicolumn{1}{|c|}{ Junior } & \multicolumn{1}{|c|}{ Senior } & \multicolumn{1}{|c|}{$\begin{array}{c}\text { Graduate } \\
\text { Student }\end{array}$} & Total \\
\hline No responses & $158(84.5)$ & $123(89.9)$ & $90(90)$ & $109(83.8)$ & $106(85.5)$ & $586(86)$ \\
\hline Yes responses & $29(15.5)$ & $17(12.1)$ & $10(10)$ & $21(16.2)$ & $18(14.5)$ & $96(14)$ \\
\hline Total & 187 & 140 & 100 & 130 & 124 & $681(100)$ \\
\hline
\end{tabular}

$x^{2}=2,721, d f=4 ; p=0.61$

The second research question focused on academic misconduct, specifically, whether academic misconduct occurs if one submits a paper written by someone else, either in part or whole. This was also a yes/no question (see Appendix A, question 6). Table 4, which is a cross-tabulation of academic classifications and question 6 , depicts that the majority of all students $(96.9 \%)$ indicate that it is academic misconduct if one submits a paper written by someone else, either in part or whole. A chi-square contingency table was calculated and the likelihood ratio chi-square was not significant at the 0.05 alpha level $(x 2=5.371, d f=4, p=0.25)$.

Table 4:

Cross-tabulation of academic classification by submission of paper written by someone else

\begin{tabular}{|l|l|l|l|l|l|l|}
\hline & $\begin{array}{c}\text { Freshman } \\
(\%)\end{array}$ & Sophomore & \multicolumn{1}{|c|}{ Junior } & \multicolumn{1}{|c|}{ Senior } & $\begin{array}{c}\text { Graduate } \\
\text { Student }\end{array}$ & Total \\
\hline No responses & $8(4.3)$ & $4(2.9)$ & $5(5)$ & $1(0.8)$ & $3(2.4)$ & $21(3.1)$ \\
\hline Yes responses & $179(95.7)$ & $136(97.1)$ & $95(95)$ & $129(99.2)$ & $121(97.6)$ & $660(96.9)$ \\
\hline Total & 187 & 140 & 100 & 130 & 124 & $681(100)$ \\
\hline
\end{tabular}

$x^{2}=5.371, d f=4 ; p=0.25$ 
The third research question focused on opinions regarding acceptability of copying/ pasting passages from the internet into one's assignments, papers, etc., without citing the original source (see Appendix A, question 5). Table 5 presents the responses to question 5 (yes/no) by academic classification. The responses to the question indicate that almost $97 \%$ of all respondents reject the acceptability of this action. The likelihood ratio chi-square contingency table was also not significant at the 0.05 alpha level $(x 2=1.191, d f=4, p=0.89)$.

Table 5:

Cross-tabulation of academic classification by acceptability to copy/paste from the internet without citing the original source

\begin{tabular}{|l|l|l|l|l|l|l|}
\hline & \multicolumn{1}{|c|}{$\begin{array}{c}\text { Freshman } \\
(\%)\end{array}$} & Sophomore & \multicolumn{1}{|c|}{ Junior } & \multicolumn{1}{|c|}{ Senior } & \multicolumn{1}{c|}{$\begin{array}{c}\text { Graduate } \\
\text { Student }\end{array}$} & \multicolumn{1}{|c|}{ Total } \\
\hline No responses & $182(97.3)$ & $135(96.4)$ & $97(90)$ & $126(96.9)$ & $118(95.2)$ & $658(96.6)$ \\
\hline Yes responses & $5(2.7)$ & $5(3.6)$ & $3(3)$ & $4(3.1)$ & $6(4.8)$ & $23(3.4)$ \\
\hline Total & 187 & 140 & 100 & 130 & 124 & 681 \\
\hline
\end{tabular}

$X^{2}=1.191, d f=4 ; p=0.89$

The fourth research question focused on respondents' impressions that cheating at Samford University was widespread (see Appendix A, question 13). Table 6 depicts all students' responses to question 13 . The majority of respondents $(45 \%)$ either disagreed or strongly disagreed with this statement, while only $15 \%$ either strongly agreed or agreed. It is noteworthy to recognise that a large number of the students were undecided $(38 \%)$ concerning this issue. An ANOVA was used in analysing the data (Likert scale) among the academic classifications, which did not reveal any significant differences $(F=1.54, p=0.188)$ at the 0.05 alpha level.

Table 6:

Cheating at this institution is widespread

\begin{tabular}{|c|c|c|c|c|}
\hline $\begin{array}{c}\text { Strongly Agree } \\
(\%)\end{array}$ & Agree & Undecided & Disagree & $\begin{array}{c}\text { Strongly } \\
\text { Disagree }\end{array}$ \\
\hline $14(2.1)$ & $89(13.1)$ & $265(38.9)$ & $265(38.9)$ & $47(6.9)$ \\
\hline
\end{tabular}

Total=680 $(1$ missing $) F=1.54, p=0.188$

The fifth research question focused on paraphrasing words from an original text and then using them without documentation (see Appendix A, question 24). Table 7 depicts all responses of the Likert-type scale regarding this question. The majority of respondents $(64 \%)$ either agreed or strongly agreed with the question, i.e., it would be plagiarism to alter words from a source (book, article, internet, etc.) and then utilise the rewrite without documentation. Only about $20 \%$ either disagreed or strongly disagreed. An ANOVA was also used in analysing the Likert scale among academic classes. There was not a significant difference among the academic classifications $(F=2.21, p=0.067)$ at the 0.05 alpha level.

Table 7:

Changing words around from a source without documentation is plagiarism

\begin{tabular}{|c|c|c|c|c|}
\hline $\begin{array}{c}\text { Strongly Agree } \\
(\%)\end{array}$ & Agree & Undecided & Disagree & $\begin{array}{c}\text { Strongly } \\
\text { Disagree }\end{array}$ \\
\hline $140(20.6)$ & $269(43.5)$ & $102(15.0)$ & $116(17.0)$ & $23(3.4)$ \\
\hline
\end{tabular}

Total $=677$ (4 missing) $F=2.21, p=0.067$ 
The sixth and final research question this paper sought to address was faculty clarification concerning academic integrity. Question 32 (see Appendix A, question 32) was designed to address this issue. Table 8 portrays the responses to this question. A very high percentage (60\%) either agreed or strongly agreed with the statement, i.e., most students indicated that they wished faculty would clarify their expectations for academic integrity for each course the student took, while almost $23 \%$ were undecided. An ANOVA was also used in analysing the Likert scale among academic classes. There was not a significant difference among the academic classifications $(F=2.05, p=0.086)$ at the 0.05 alpha level.

Table 8:

Students' desire for clarification from faculty concerning academic integrity expectations for each course

\begin{tabular}{|c|c|c|c|c|}
\hline $\begin{array}{c}\text { Strongly Agree } \\
(\%)\end{array}$ & Agree & Undecided & Disagree & $\begin{array}{c}\text { Strongly } \\
\text { Disagree }\end{array}$ \\
\hline $106(15.6)$ & $304(44.6)$ & $156(22.9)$ & $87(12.8)$ & $23(3.4)$ \\
\hline
\end{tabular}

Total=676 (5 missing) $F=2.05, p=0.086$

\section{Discussion}

The initial purposes of this study were made difficult by several factors. First, there are many variables that could cause entirely different results if not carefully considered. For example, the mere definition of cheating, academic misconduct, plagiarism, etc., can be interpreted differently by many students, as well as by different researchers. Second, variables such as college/university size, academic classification, type of institution, etc., all have an effect on the outcome of any plagiarism study. Third, there is apparently a great deal of difference between what students say is wrong and what they actually do. And fourth, contextual factors related to peers are very significant while extremely difficult to measure. When all these factors, plus numerous others are considered, it is very difficult to compare the student population of Samford University to that of another similar university. The reader must keep these concerns in mind when scrutinising data from various studies.

According to the student survey results depicted in Table 3, 14\% ( $N=96$ of 681 students) reported "Yes," that they had previously cheated on a test/exam. The percent who indicated yes is relatively even across all academic classifications. Samford University's Office of the Vice President and Dean of Students has accumulated unpublished data from annual freshmen surveys. One question on the survey pertains to academic dishonesty, specifically "In what ways have you seen academic dishonesty?". One of the choices is "Cheating on a test" (meaning have you seen anyone cheat on a test). For the current academic year (2007-2008), of the 438 freshmen (total eligible 713 ) that responded to the Dean of Student's survey, $16 \%$ indicated that they had seen "Cheating on a test". This $16 \%$ response rate is remarkably comparable to the current survey of freshmen who indicated $(15.5 \%)$ that they had previously cheated on a test/exam (see Table 3 ). In fact, a closer examination across all years of the Dean of Student's data revealed that the percentage of students who selected "Cheating on a test" range from $9 \%-19 \%$ for inclusive years 2000-2008. Cheating on tests/exams at Samford University appears to be relatively low when the current academic misconduct/plagiarism survey is compared to the freshman-only survey administered by the Office of the Vice President and Dean of Students.

At first glance (Table 3), it appears that Samford students cheat less than other similar studies; however, this apparent conclusion has some caveats. A landmark study of college cheating that was conducted in 1963 found that $39 \%$ of students acknowledged one or more incidents of serious test or exam cheating (McCabe, 
2005). McCabe conducted a follow-up study and by 1993, exam cheating had increased to $64 \%$. McCabe (2005), however, further explains that it was difficult to tell how much of this change represented an actual increase in cheating or simply a reflection of changing student attitudes about cheating. Regardless of the type of plagiarism study performed, it is extremely difficult to measure increases (or decreases) of plagiarism due to probable changing attitudes toward cheating. Even cheating on coursework, as opposed to an exam, can be viewed differently. A study by Harries and Rutter found that pharmacy "students did not perceive coursework to constitute dishonest behaviour to the same extent as examinations" (Harries \& Rutter, 2005, p. $54)$.

One of the most classic incidents of academic misconduct is a student submitting an assignment/written paper prepared by another (question number 6). Table 4 sought to determine student labeling this behavior as plagiarism. Almost $97 \%$ of students answered "Yes," that they considered this an act of plagiarism. Of all the yes/no questions asked, question 6 had the highest percentage that answered yes. In a 1994 study of cheating at small colleges, Graham et al. found a similar percentage breakdown regarding this type of plagiarism. They surveyed 480 students from two Midwest colleges, of which approximately $70 \%$ of the subjects were enrolled in a private Catholic college and the other $30 \%$ were from a community college. Of the students surveyed in Graham's study, $95.9 \%$ stated that "having someone write a term paper for you" (Graham et al., 1994, p. 256) would be cheating. Samford's data is very similar to Graham's study, in that Samford's students report only a slight increase from these numbers despite an intervening 14 years.

Copying/pasting information from the internet with no attribution or citation source is possibly the most controversial plagiarism issue among students. Table 5 indicates almost $97 \%$ of all students concluded that it is not acceptable to copy/paste information from the internet with no attribution or citation source. It should be carefully noted that the question did not ask if students had actually copied/pasted with no citations, but rather asked if this practice is acceptable. It has already been asserted in the Introduction section that most students do not view copying/pasting from the internet as plagiarism or cheating. Samford students are clearly reporting that they think this type of information use is wrong; however, it is the authors' opinion that there is a vast difference in what students state is ethically wrong, versus what their actual practice is. For example, in one of McCabe's (2001) studies, $10 \%(\mathrm{~N}=2,200)$ of the college students reported copying a few sentences from a website without footnoting them, versus $68 \%$ of the same students who thought that this behavior was serious. In the Samford University study, almost $20 \%$ of the respondents indicated that they had previously cheated in some manner on written class assignments (question 11). Yet, $97 \%$ of the respondents indicated that they considered submitting a paper written by someone else, either in part or whole, to be academic misconduct (question 6). Undoubtedly, cheating in some manner on written assignments may or may not include submitting a paper by someone else; however, the two issues are both instances of academic dishonesty. In light of this discrepancy in percentages, it seems reasonable to assume that although $97 \%$ of students regard copying/pasting without documentation as plagiarism, at least some percentage of those responding have actually engaged in the practice.

Question 13 (cheating at this institution is widespread) was designed to solicit students' opinions concerning extensive cheating at Samford University. Table 6 depicts the responses of all students. Approximately $46 \%$ either disagreed or strongly disagreed with this statement. A large number of students were undecided $(38.9 \%)$. The subjective nature of this question makes drawing any significant conclusions untenable; the responses do, however, suggest that there is not rampant cheating behavior on campus. The percentage of students who perceive cheating to be a widespread problem $(15.2 \%)$ is comparable to the percentage who reported, when they were surveyed as freshmen, having seen cheating on tests $(16 \%)$ and also to the percentage who self-reported cheating on a text/exam in this survey $(15.5 \%)$ (Table 3$)$. 
For students, paraphrasing is likely one of the least understood academic endeavors either because of the student's lack of ability or lack of understanding. Taking words from the original text (source) for use in one's own paper has been a cause of controversy for a long time. Wood (2004) also states that students are often very confused about paraphrasing. In a study of 2,829 college students, students had the most difficulty with paraphrasing questions from a tutorial-based quiz program that assessed students' basic understanding of plagiarism, penalties if caught, and what needs to be cited (Jackson, 2006). In another study by Ashworth and Bannister (1997), students understood the misuse of verbatim statements as plagiarism; however, paraphrasing passages into their own words appeared to be a lesser offense.

Approximately $64 \%$, almost two-thirds, of the Samford students either agreed or strongly agreed that changing words from a source (book, article, internet, etc.) and then using them without documentation is plagiarism (see Table 7). Slightly over $20 \%$ either disagreed or strongly disagreed with the statement, meaning that these students thought that it was acceptable to change words from a source without documentation. It would appear that Samford students are likewise confused about paraphrasing, similar to the respondents in Wood's study. A closer inspection of question 24 reveals that among the academic groups, freshman and sophomores had the largest percentage $(40 \%)$ of disagree responses, meaning that they disagreed with question 24.

In addition to question 24, a similar question (see Appendix A, question 25) was asked, which stated that paraphrasing the ideas of others with documentation is not plagiarism. Both questions address the same issue, i.e., paraphrasing as related to plagiarism. The responses for question 25 are also very similar to question 24 . Approximately $70 \%$ either strongly agreed or agreed with this statement, as compared to $64 \%$ that strongly agreed or agree with question 24 . About $21 \%$ of the responds either disagreed or strongly disagreed with question 25 , compared to $20 \%$ with question 24 . Similarly for question 25 , freshmen and sophomores had the largest percentage (33\%) that disagreed. Questions 24 and 25 are very similar with comparable results; thus it appears that the respondents were consistent with their answers.

Students' relative lack of certainty concerning paraphrasing, as evidenced in questions 24 and 25, as compared to the percentages reported for cutting/pasting without documentation, using another's paper, and exam cheating is indicative of the confusion surrounding paraphrasing. Students clearly need more instruction in correct paraphrasing and citation so that they will feel more comfortable making such a judgment. Although there was not a significant difference among classifications, freshmen indicated the least surety on this topic. As the final research question indicates, students very much desire more course-specific instruction about plagiarism from their professors.

The Samford survey did not address the issue of citing or paraphrasing common knowledge information. "The world is round," for instance, would not necessarily require a citation, unless the research paper were exploring all the various theories regarding the shape of the world. In other words, the context from which the research paper is written likely determines how citations (including paraphrasing) will be accomplished. Complicating this issue are the instructors' interpretations of what exactly is common knowledge. This is even further complicated by the apparent notion of what students view as "common knowledge," e.g., the internet.

One of the most intriguing results of this study for the authors was the responses for question 32 (see Appendix A), which sought to address the importance of faculty clarification of academic integrity for a designated course. In other responses to this survey, students indicated that they understand that submitting another's work as their 
own, copying and pasting without attribution, and, to a lesser degree, paraphrasing without attribution are unacceptable behaviors. Responses to question 32 indicate that even though students understand these issues of academic integrity, over half of them still want faculty to delineate acceptable vs. unacceptable practices on a courseby-course basis. A high percentage $(60 \%)$ of students either strongly agreed or agreed with the statement of desiring faculty to clarify very specifically their expectations for academic integrity for each course (see Table 8). As a broad generalisation, one might expect that freshmen and sophomores would be the largest academic group to agree with this question due to their newness in academic endeavors. A closer examination of the data reveals this assertion to be true. Sixtyseven percent of the freshman either agreed or strongly agreed with question 32 , while $59 \%$ of sophomores either agreed or strongly agreed.

Samford students' desires for clarification about academic integrity from faculty reflect the recommendations of other investigators. For example, McCabe (2005) stipulates that when faculty clarify course expectations, it becomes one of the most important and helpful items they can do toward prevention of plagiarism. Graham et al. also voices that "faculty should clearly define what is acceptable behavior in their class and what is not" (Graham et al., 1994, p. 259). Turrens probably states it best by proposing that instructors must provide students with the foundation of ethical conduct in all types of classes, thereby "openly explaining and discussing what constitutes plagiarism, data fabrication, and manipulation" (Turrens \& Davidson, 2001, p. 65).

\section{Limitations}

There were a few limitations to the study design. First and foremost, it was assumed that the student respondents answered the questions honestly and their answers were their own and without influence. Second, there was no way to determine with any degree of certainty if a non-Samford student had participated in the survey. If a respondent checked "Not a Samford Student" (see Appendix A, question 1), that survey was not included in the data or analysis. Although some type of authentication (e.g., proxy server) could have been imposed thus forcing a student log-in, the authors concluded that imposing any type of log-in procedure would likely impede participation. It is possible therefore that students could have accessed the survey more than once and could have thus skewed results.

\section{Conclusions}

There is no doubt that plagiarism and other types of academic misconduct are on the rise for a variety of reasons (Graham et al., 1994; Genereux \& McLeod, 1995).

Students seemingly have the notion that internet information is public knowledge and thus free from intellectual property rights; therefore, they do not seem to think internet information needs to be cited for academic purposes. Exactly why students cheat remains elusive, even though many thoughts and theories have been offered and all have elements of truth. Studies regarding academic dishonesty, including plagiarism and cheating, are difficult to quantify and interpret primarily due to possibly changing attitudes by students, i.e., does the study reflect real change or has the attitude of the student(s) merely changed. This is a significant issue for all academic misconduct studies. Perhaps one of the primary reasons for this difficulty is the peer-related factors that greatly influence academic dishonesty, which are very complicated to quantify. Based on this premise, plagiarism studies, especially retrospective studies, should be carefully scrutinised.

The vast majority of Samford University students indicated that they had not previously cheated on tests/exams, which was somewhat lower than similar studies, but caveats remain with this assertion. Additionally, the percentage of freshmen who admitted cheating on a test/exam was almost identical to other Samford internal 
survey studies. Samford students had about the same misunderstanding or misuse of paraphrasing as other studies. Furthermore, the importance of faculty clarification of academic integrity for a designated course was surprisingly high, but corroborated by other researchers.

Even though comparative data with other institutions might signify that Samford students cheat less, or that a greater majority of Samford respondents indicate that copying/pasting without proper citations is unacceptable, the authors assert that one should be cautious at this general conclusion. Based upon factors such as the "situational ethics" syndrome, slightly different phrasing of questions in other studies, and other student variables that confound the data, studies should be vigilantly compared. Obviously, it is hoped that Samford University's Christian environment minimises academic dishonesty tendencies; however, this cannot be asserted for certain.

\section{References}

Ashworth, P., \& Bannister, P. (1997). Guilty in whose eyes? University students' perceptions of cheating and plagiarism in academic work and assessment. Studies in Higher Education, 22(2), 187-203.

Dye, J. (2007). To catch a thief. Econtent, 30(7), 32-37.

Ercegovac, Z., \& Richardson, J. V., Jr. (2004). Academic dishonesty, plagiarism included, in a digital age: A literature review. College \& Research Libraries, 64, 306.

Genereux, R. L., \& McLeod, B. A. (1995). Circumstances surrounding cheating: A questionnaire study of college students. Research in Higher Education, 36, 678 -704 .

Graham, M. A., Monday, J., O'Brien, K., \& Steffen, S. (1994). Cheating at small colleges: An examination of student and faculty attitudes and behaviors. Journal of College Student Development, 35, 255-260.

Harries, R., \& Rutter, P. M. (2005). Cheating by pharmacy students: Perceptions, prevalence and comparisons. Pharmacy Education, 5(1), 54.

Howard, R. M. (2008). Bibliographies for Composition and Rhetoric. Retrieved February 5, 2008, from http://wrt-howard.syr.edu/bibs.html

Isserman, M. (2003). Plagiarism: A lie of the mind. Chronicle of Higher Education, Chronicle Review, 39, 12.

Jackson, P. A. (2006). Plagiarism instruction online: Assessing undergraduate students' ability to avoid plagiarism. College \& Research, 67(5), 423.

Kraus, J. (2002). Rethinking plagiarism: What our students are telling us when they cheat. Issues in Writing, 13(1), 80-95.

Madray, D. (2007). Developing Students' Awareness of Plagiarism: Crisis and Opportunities. Retrieved October 14, 2008, from http:// www.webpages.uidaho.edu/ mbolin/madray.htm

McCabe, D. (2001). Cheating: Why students do it and how we can help them stop. American Education, Winter, 38-43.

McCabe, D. L. (2005). It takes a village: Academic dishonesty and educational opportunity. Liberal Education, 91(3), 26-31.

McCabe, D. L., Trevino, L. K., \& Butterfield, K. D. (2004). Cheating in academic institutions: A decade of research. Ethics \& Behavior, 11(3), 222-223.

PHPESP. (2008). Butterfat, LLC. Retrieved August 6, 2008, from http:// www.butterfat.net/wiki/ Projects/phpESP/

Samford University. (2007). 2007-2008, Student Handbook and Academic Planner. Birmingham. AL: Author. (Also available on Samford University's Web site: http://www.samford.edu/studentaffairs/ studenthandbook.pdf ) 
Turrens, J. F., \& Davidson, E. (2001). Data manipulation by undergraduates and the risk of future academic misconduct. Council on Undergraduate Research Quarterly, Dec, 65.

Wood, W. (2004). Academic original sin: Plagiarism, the internet, and librarians. The Journal of Academic Librarianship, 30(3), 238-239.

\section{Acknowledgements}

The authors gratefully acknowledge the counsel of Dr. Tomas Woolley, Professor of Economics, Finance, and Quantitative Analysis, Samford University, for his statistical support and advice.

The opinions, analysis and conclusions of this paper are strictly the authors' and do not reflect any official position regarding academic misconduct or plagiarism from the Samford University administration.

\section{About the authors}

Robert H. Schrimsher is Professor of Pharmacy Practice and Pharmacy Librarian at Samford University, Birmingham, AL. He did his undergraduate work in sociology and psychology at Lamar State College of Technology (BS, 1966) and graduate studies at Stephen F. Austin State College (M.Ed., 1967), the University of Alabama, (MILS, 1996), and the Catholic University of America (Ed.D.,1982). His research has focused on drug information resources within pharmacies and classroom technology endeavors. Schrimsher's publications have appeared in the Drug Information Journal, the American Journal of Pharmaceutical Education, and the International Journal of Pharmacy Education and Practice. Prof Schrimsher has served on the editorial boards of the Drug Information Journal and the Journal of the Medical Library Association. He has also founded and established the International Journal of Pharmacy Education and Practice, serving as the founding editor from 2002 to July, 2010.

Lori Northrup is chair of the Reference Department at Samford University Library. She completed her graduate work in library and information studies at the University of Alabama (M.L.I.S., 2001). Her research interests include pedagogy of reference, assessment of learning outcomes in information literacy, and curricula-driven collection management. She is an assistant editor of the International Journal of Pharmacy Education and Practice and serves as president-elect of the Alabama Association of College and Research Libraries.

Susan Alverson is presently the Associate Dean of Student and Alumni Affairs and Director of Continuing Education at Samford University, McWhorter School of Pharmacy. Her BS degree in pharmacy is from the University of Wisconsin; she obtained a masters in hospital pharmacy from Virginia Commonwealth University, and then a masters and doctorate in public administration from the University of Southern California. At present Dr. Alverson teaches pharmacy math, sterile products, and a course in leadership at Samford. She is the primary instructor in an ALSHP certification exam preparatory class for technicians. Her work history includes hospital and community pharmacy in both administration and practice roles, as well as in longterm care consulting, home health infusion and as a director of a program for addicts. While in Virginia, she served as director of pharmacy for state and local public health system pharmacies. 
Note: the survey information within is not the same format as was depicted on the Web -base PHP survey.

\section{Samford University Survey on Academic Plagiarism/Misconduct \\ Term Definitions-- \\ Plagiarism: Generally, the failure to attribute words, ideas, or findings to their true} authors.

Academic Misconduct: Generally, defined as all acts of dishonesty in an academic or related matter, such as cheating, abetting, plagiarism, etc.

1. Select your academic classification from the drop-down menu:

(Freshman, Sophomore, Junior, Senior, Graduate Student, Other (part-time, etc.), Not a Samford Student)

2. Please choose from the drop-down menu the school/college that best describes your major area of study. (For Arts \& Sciences majors only, skip this question and go to question 3 ):

(School of Business, School of Divinity, School of Education and Professional Studies, School of Nursing, School of Performing Arts, School of Pharmacy, School of Law)

3. For Arts \& Sciences majors only, please choose from the drop-down menu the department that best describes your major area of study:

(Art, Biology, Chemistry, Classics, Communication Studies, English, Geography, History, Journalism and Mass Communication, Mathematics and Computer Science, Philosophy, Physics, Political Science, Psychology, Religion, Sociology, World Languages)

The following questions were Yes/No questions.

4. If a student submitted an assignment with passages copied from a book or article, with no attribution or citation, would you consider this plagiarism.

5. It is acceptable to copy/paste passages from the Internet to your assignments, papers, etc., without citing the original source.

6. If you submit a paper written by someone else, either in part or whole, would you consider this academic misconduct?

7. Is purchasing a paper from a papermill, Web site, or other sources, an example of academic misconduct?

8. Is cheating just another way to survive in the academic world?

9. I am aware that Samford University has an official academic integrity statement.

10. I have previously cheated on a test/exam.

11. I have previously cheated in some manner on written class assignments.

The following questions were a Likert-type rating scale. (Strongly agree, agree, undecided, agree, strongly disagree)

12. My student friends rarely plagiarize.

13. Cheating at this institution is widespread. 
14. Many students that I know have downloaded a complete paper from the Internet and submitted the paper as their own assigned work.

15. Most student friends that I know are academically honest students.

16. Academic dishonesty is OK as long as you don't get caught.

17. I have plagiarized only a small part of an assignment paper.

18. It is necessary to plagiarize a little because good grades are so competitive.

19. Using information on the Internet without acknowledgement (citing) is plagiarism.

20. I really don't know how to cite something from the Internet.

21. Plagiarism is only a concern if you get caught.

22. Most of my instructors give stern warnings about plagiarism at some point during the class.

23. It is very easy to plagiarize a paper without my instructor knowing.

24. Changing words around from a source (book, article, Internet, etc.) and then using them without documentation is plagiarism.

25. Paraphrasing the ideas of others with documentation is not plagiarism.

26. I understand the penalties of plagiarism if caught.

27. Faculty that I know do not seem to be concerned with cheating.

28. Cheating just isn't a big deal.

29. Samford University integrity policies are ill-defined.

30. I am more concerned with what my peers think about me cheating than the faculty/administration.

31. Most faculty that I know appear to ignore cheating.

32. I wish faculty would clarify very specifically their expectations for academic integrity for each course I take. 